\title{
Thermal and lighting perception in four fully glazed office buildings in Santiago, Chile
}

\author{
Claudio Vásquez ${ }^{\mathrm{a}, *}$, Felipe Encinas Pino ${ }^{\mathrm{a}}$, Alejandro Prieto Hoces ${ }^{\mathrm{a}}$ \\ and Carlos Aguirre Nuñez \\ ${ }^{a}$ School of Architecture, Catholic University of Chile, Providencia, Santiago, Chile \\ ${ }^{b}$ School of Architecture, Desarrollo University, San Carlos de Apoquindo, Las Condes, Santiago, Chile
}

Received: 15 October 2013

Accepted: 21 November 2013

\begin{abstract}
This paper is part of a general research project whose main objective is to establish a baseline for post-occupancy energy consumption and indoor environmental quality for office buildings in Santiago, Chile. This study aims at understanding how architectonical variables relate to, and can even determine, user comfort perception. Thus, one-year continuous monitoring in several floors at four office buildings was performed and seasonal surveys were completed. Survey participants were asked a series of questions regarding spatial orientation and comfort perception in their workspace.

The data from the comfort survey and onsite measurements such as season of the year, case study, type of workspace and possibility of an outdoor view from the workstation were contrasted with the components obtained by a Principal Component Analysis (PCA). Three components were selected from the PCA, and three Maps of Perception (MP) were produced. These maps were then analyzed and interpreted so as to obtain information on the general perception of thermal and lighting comfort at workspaces within several office buildings in Santiago.
\end{abstract}

Keywords: Office buildings, thermal comfort, architectural design

\section{Introduction}

Office building development in Santiago has increased dramatically since the end of the 20th century. This growth has brought along significant technology transfer in construction methods and the subsequent sophistication of building components. However, high building technology standards do not necessarily correlate with good indoor environmental conditions or efficient energy consumption. Quite the contrary, high energy requirements for cooling purposes and glare recurrently appear in office buildings in Santiago.

Indeed, according to a sensitivity analysis conducted by Pino, Bustamante, Escobar and Encinas (2012), the factor that best correlates with energy demand (for both heating and cooling) in Santiago, is the ratio of glazed surfaces versus opaque areas of the vertical envelope. Within the office buildings here studied, window-to-wall ratios of $20 \%$ show energy demands below $40 \mathrm{kWh} / \mathrm{m}^{2}$ (in the best case, as low as $25 \mathrm{kWh} / \mathrm{m}^{2}$ ) while fully glazed façade buildings can reach up to $155 \mathrm{kWh} / \mathrm{m}^{2}$. This is particularly significant in Santiago, where building technologies originally associated to the improvement

\footnotetext{
${ }^{*}$ Corresponding author: Claudio Vásquez, School of Architecture, Catholic University of Chile. 1916 El Comendador str. Providencia, Santiago, ZIP: 7530091, Chile. Tel.: +56 9 92826305; E-mail: clvasque@uc.cl.
} 
of environmental or energy efficiency issues are used mainly for aesthetic reasons, failing sometimes to fulfill their primary intention (Encinas, 2004).

User behavior and building energy performance are highly correlated. The presence of elements such as scheduled indoor gains or ventilation (by means of manually controlled windows) can lead to variations in the energy consumption. Various studies have proven that similar buildings can present large differences in thermal behavior, which suggests that user behavior exerts a strong influence (Guerra, 2011). Thermal comfort for those working in an office building depends on parameters such as orientation, outdoor view from workspace, type of workspace (open floor plan, individual or shared office), seasonal or personal characteristics. This is true even in buildings as those here described in which indoor air is mechanically conditioned and controlled. In the case of dwellings, for instance, Andersen, Toftum and Olesen (2009) proposed that given the strong link between user behavior and energy consumption, thermal comfort needs to be characterized in order to forecast user interaction with building control mechanisms (window opening and closing, use of heating, use of artificial lighting, and use of solar shading). A similar situation occurs in office buildings, as showed by a survey on thermal comfort and workplace occupant satisfaction conducted in 16 German low energy office buildings which proved that indoor environment control by users and the perceived impact of their intervention strongly influence thermal comfort level (Wagner, Gossauer, Moosmann, Gropp, \& Leonhart, 2007). Zhang \& Altan (2011) performed a comparative study on the occupant comfort between a conventional (mechanically conditioned) high-rise office building and an environmentally concerned building (including a south-facing atrium with the aim of driving the passive stack natural ventilation) in Sheffield, UK. According to their study, there is a significant difference between both buildings in terms of their thermal and visual comfort. The conventional building was characterized by overheating, poor ventilation, glare and excessive solar radiation, which may be explained by the presence of extensive glazed surfaces on its envelope and the excessive dependence on its HVAC system (evidenced by the difficulty to open windows, for example).

This situation explains our interest in establishing a baseline of post-occupancy energy consumption and indoor environmental quality of office buildings in Santiago, Chile, by means of continuous monitoring of several floors in four office buildings and an online seasonal survey.

\section{Background}

From a climatic point of view, Santiago's warm temperate weather with a dry summer reminds us of California, North Africa, the Mediterranean zone and the Persian Gulf as described in Köppen's climatic classification. A short winter rainy period and a long dry season are characteristic. Seasonal thermal oscillation reaches $13^{\circ} \mathrm{C}$ (summer vs winter average temperatures), and daily thermal oscillations range between 14 and $16^{\circ} \mathrm{C}$ (maximum vs minimum daily temperatures). The radiation level in the horizontal plane is between 1.380 and $1.666 \mathrm{kWh} / \mathrm{m}^{2}$ year, equivalent to Chile's northern desert coastal zone.

From a descriptive point of view, high standard office buildings in Santiago exhibit the most innovative and complex façade solutions available in Chile today. A review of 43 office buildings built in Santiago between 1997 and 2010 revealed that $64 \%$ of the cases use curtain wall; $78 \%$ has an airtight façade solution (no operable windows); $66 \%$ has no solar protection and $58 \%$ has window to wall ratio (WWR) in the range between $75 \%$ and $100 \%$. Shape wise, most are slender prisms and have a low thermal mass (Table 1). 
Table 1

Representative characteristics of office buildings in Santiago

\begin{tabular}{|c|c|c|c|c|c|c|c|c|}
\hline \multicolumn{4}{|c|}{ Building Shape Parameters } & \multicolumn{5}{|c|}{ Facade System Parameters } \\
\hline & $\begin{array}{c}\text { More } \\
\text { Compact } \\
(\mathrm{MC})\end{array}$ & $\begin{array}{c}\text { Balanced } \\
\text { Compact } \\
(\mathrm{BC})\end{array}$ & $\begin{array}{c}\text { Less } \\
\text { Compact } \\
\text { (LC) }\end{array}$ & & $\begin{array}{c}\text { Curtain } \\
\text { wall } \\
(\mathrm{CW})\end{array}$ & $\begin{array}{c}\text { Nonstructural } \\
\text { facade } \\
\text { (NF) }\end{array}$ & $\begin{array}{l}\text { Loadbearing } \\
\text { facade } \\
\text { (LF) }\end{array}$ & $\begin{array}{l}\text { Mixed } \\
\text { facade } \\
\text { (MF) }\end{array}$ \\
\hline \multirow[t]{2}{*}{$\begin{array}{l}\text { Shape Factor } \\
\text { (SF) }\end{array}$} & $65 \%$ & $21 \%$ & $14 \%$ & $\begin{array}{l}\text { Facade Type } \\
\text { (FT) }\end{array}$ & $65 \%$ & $16 \%$ & $5 \%$ & $14 \%$ \\
\hline & $\begin{array}{c}\text { High } \\
\text { Proportion } \\
(\mathrm{HP}) \\
\end{array}$ & $\begin{array}{c}\text { Average } \\
\text { Proportion } \\
\text { (AP) }\end{array}$ & $\begin{array}{c}\text { Low } \\
\text { Proportion } \\
\text { (LP) } \\
\end{array}$ & & $0 \%-24 \%$ & $25 \%-49 \%$ & $50 \%-74 \%$ & $75 \%-100 \%$ \\
\hline $\begin{array}{l}\text { Floor Plan } \\
\text { Proportion (PP) }\end{array}$ & $33 \%$ & $47 \%$ & $20 \%$ & $\begin{array}{c}\text { Window-to- } \\
\text { Wall Ratio (WW) }\end{array}$ & $0 \%$ & $9 \%$ & $16 \%$ & $75 \%$ \\
\hline
\end{tabular}

Thus, if we combine climatic and constructive features, the general hypothesis is that fully glazed office buildings in Santiago do not respond adequately to their climate context, leading to indoor discomfort and the need for high energy consumption in order to achieve comfortable conditions.

Architectural design greatly determines building energy performance, and architects normally work in interdisciplinary teams to achieve effective results. Despite these efforts, large discrepancies between what designs predict and what occupants perceive are observed. Much research is conducted trying to define and calibrate mathematical models that can be transferred to software in order to reduce these discrepancies. However, user behavior is not usually considered. In their research on the impact of occupancy parameters in office building energy simulation, Azar and Menassa (2012) did include user behavior. Their study included models representing a variety of sizes and climatic situations in the USA. The results revealed that energy use in buildings is significantly influenced by user's actions and occupancy behavioral parameters (building size and weather conditions), two parameters that are not normally considered in calculation models. Other authors as, MacDonald, Clarke \& Strachan (1999) stated that one of the main sources of uncertainty in the field of building performance simulation is user behavior. A third research paper posed that user behavior may also constitute one of the main reasons for the large and frequently observed discrepancies between the calculated or simulated energy performance and measured energy performance in real buildings (Roetzel, Tsangrassoulis, Dietrich, \& Busching, 2010; Olesen, 2011). Similarly, Yu, Fung, Haghighat, Yoshino, \& Morofsky (2011) suggested that it is difficult to completely identify the influences of user behavior through simulation due to user's behavior diversity and complexity.

This idea was further expanded by Hummelgaard, Juhl, Saebjörnsson, Clausen, Toftum and Lankilde (2007) in a study in which user's perception and indoor environment conditions in five mechanicallyand four naturally-ventilated open floor plan office buildings were characterized and compared. During the one-week study, indoor air quality was monitoring. Results revealed that temperature and $\mathrm{CO}_{2}$ concentration were the most variable features, varying in some mechanically-ventilated buildings more than in naturally ventilated cases. However, user perception did not differ greatly. This led the authors to consider that user perception may have been influenced by other building design features -lighting qualities, visual aspects, solar accessibility, etc.- and management characteristics (autonomy 
in the use of light and ventilation or air conditioning operating features). These studies led us to believe that user comfort perception and its correlation to architectural design is an area on which further research needs to be performed.

Qualitative perception data is usually collected via surveys and always needs to be contrasted with air quality measurements. Differences between perception and raw data will reveal the real performance of design, and can help us define some guidelines on office building management.

The correlation between building maintenance management services for indoor environmental quality and user satisfaction was established in two surveys carried out in Korea (Kwon, Chun, \& Kwak, 2011). The first survey was applied to seven cases. The study concludes that services maintenance and user satisfaction are correlated up to $60 \%$ and from that point on, the correlation is lost. The second survey selected two cases from the first group: one case with high services maintenance and low user satisfaction, and other with low maintenance management services and high user satisfaction. This second survey showed that user satisfaction was the same in both situations, despite the differences in adaptive opportunities (operable windows and personal thermostats). Unexpectedly, users do not seem to value environmental adaptive opportunities, thus other aspects such as design or local habits need to be taken into account to assess user perception and satisfaction.

The relationship between user perception and office building design needs to be further understood, and this paper aims to be a contribution in this direction. To do so, this paper presents a holistic approach to user comfort perception by means of a comfort perception data analysis in several office building in Santiago, Chile represented as Maps of Perception (MP) based on a Principal Component Analysis (PCA).

\section{Methodology}

Cases were selected from an extensive office building review which only included office buildings in use for over two years. A total of 43 office buildings constructed in Santiago between 1997 and 2010 were reviewed, and four cases were selected considering the main characteristics of the whole sample (Table 1). Three kinds of data were assessed in each case: indoor environmental parameters, energy consumption and comfort perception. The environmental parameters were used to compare indoor and outdoor conditions during occupied and unoccupied hours, and energy consumption measurements and comfort surveys were used to quantify operation cost and gain insight on user perception, respectively. This paper aims at comparing comfort perception (obtained from survey user's responses) with on-site measurements.

\subsection{Case description}

The four study cases share constructive, normative and orientation features, being located very near each other (Table 2; Fig. 1). Other similarities include floor surface and height, presence of a curtain-wall façade system and a high window-to-wall ratio (between $75 \%$ and $100 \%$ for all cases). Regarding glazing, all cases consider tinted hardened glass as outer layer of a double glazing, with solar heat gain coefficients between 0,28 and 0,31 . Also, all offices consider internal shading devices (screens), operated by each user.

Centralized HVAC systems (two chillers on top of the building), with fan-coils for air distribution within each office floor are also present in all four cases. In terms of management, case 1 is owned 


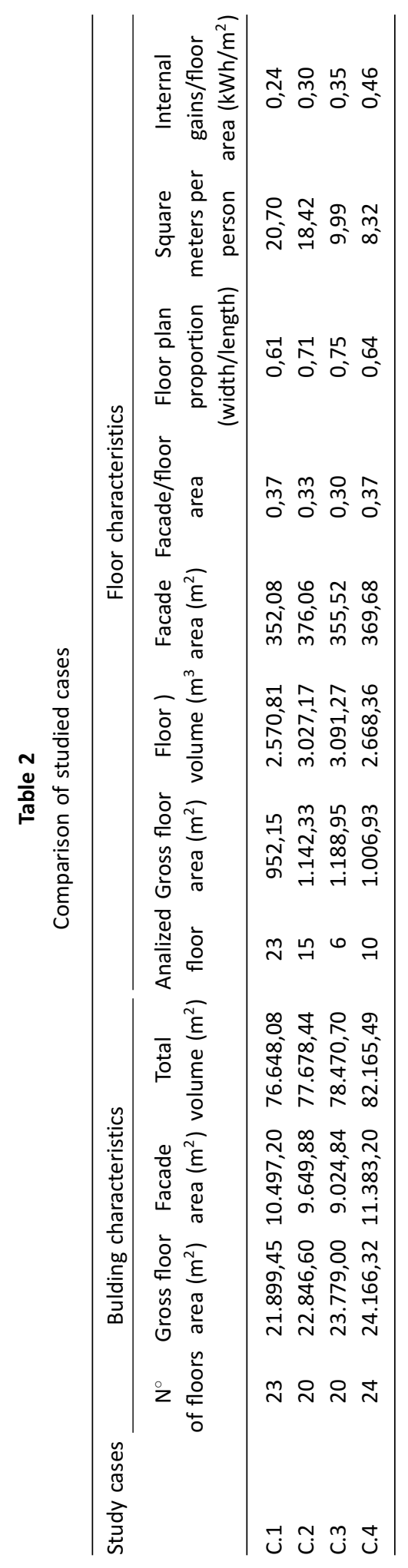




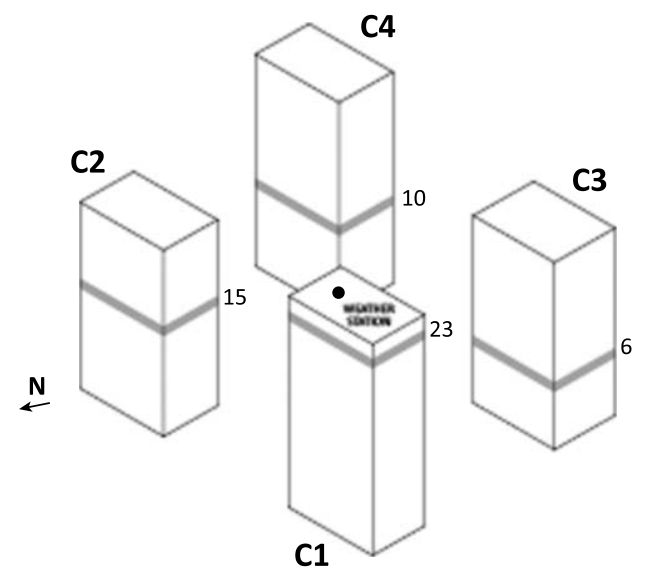

Fig. 1. Scheme of case study urban situation.

entirely by one company, and thus, managed by one administration. The other three cases are rental buildings; therefore, management may vary between floors. This study analyzed floors individually for each building.

\subsection{The instruments: Survey and on-site measurements}

The questions of the comfort survey are divided into three comfort dimensions, namely lighting, temperature, and sound, and their respective indicators (Table 3). In addition to these variables, specific on-site measurements were included for the purpose of comparison.

a) Control and segmentation: this variable registers demographical and location information for each survey participant. The demographical dimension includes indicators such as gender and age. Location information registers workspace information such as orientation and spatial characteristics (private office, shared office, open floor plan).

b) Environmental comfort perception: this variable includes three dimensions: thermal, visual and acoustic comfort each with its own variables. This variable aims to identify user level of environmental satisfaction. Also, it aims to characterize user perception regarding various attributes, architectural or adaptive, which affect thermal, visual and acoustic comfort. For example, regarding thermal comfort, the questionnaire asked about architectural attributes such as orientation or access to outdoor views. Among adaptive attributes, survey participants were asked to rate options such as being able to open windows or control the HVAC system -options that may not be available in their building. Survey participants rated their comfort perception as "relevant", "neutral" or "not relevant".

c) On-site measurements: with each survey, temperature and relative humidity measurements were registered with data loggers every 10 minutes. These data loggers were located so as to include all orientations and types of workspace (Fig. 2). This information was used to establish the percentage of hours within a certain temperature range under work schedule $\left(20-24^{\circ} \mathrm{C}\right.$ on autumn/winter and $23-26^{\circ} \mathrm{C}$ on spring/summer months), thus generating a new indicator 


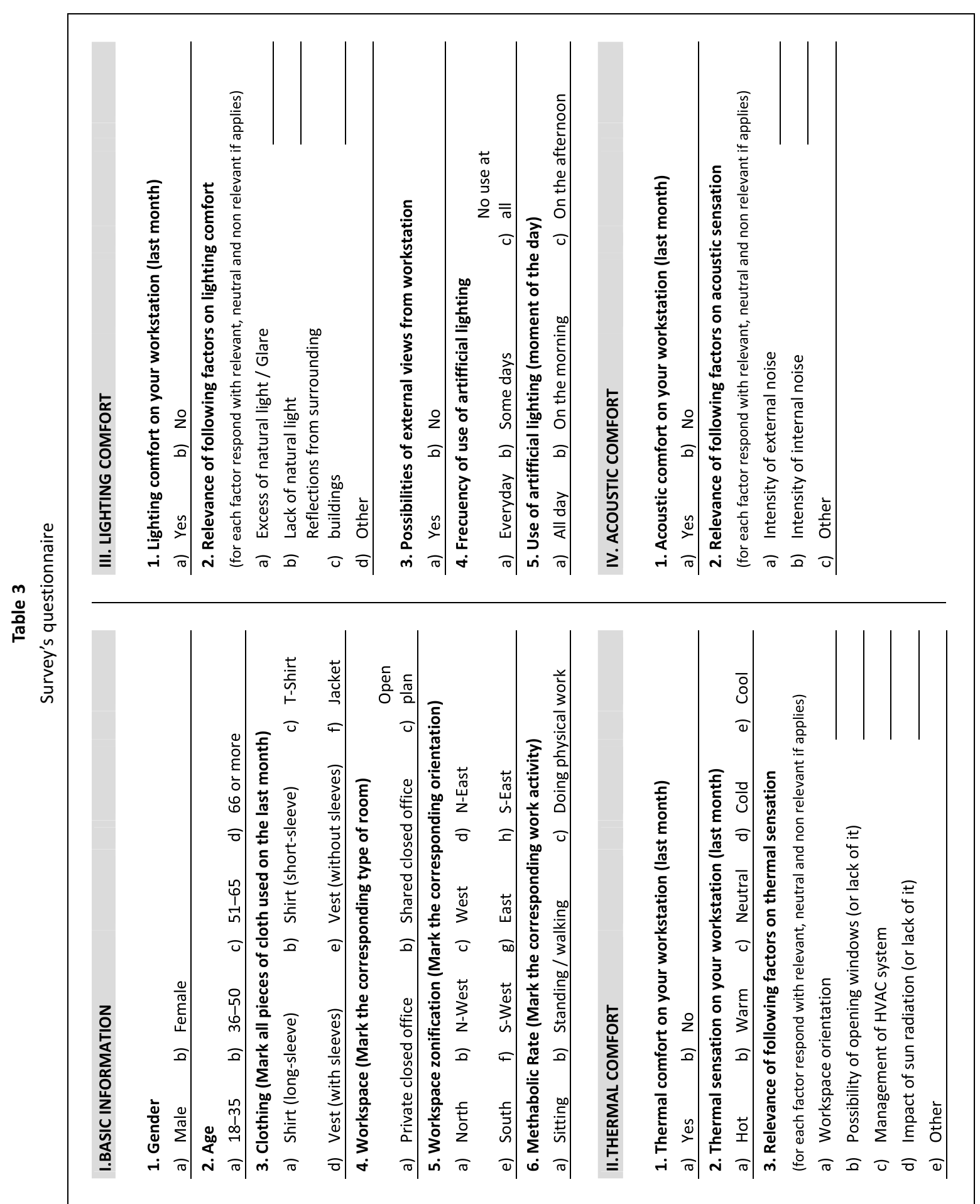



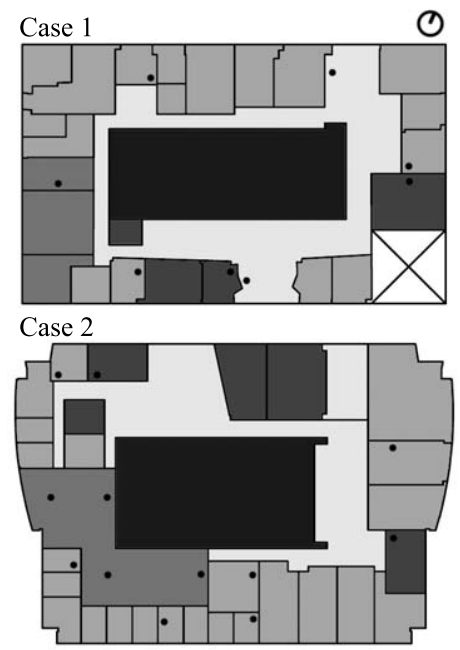

Case 3
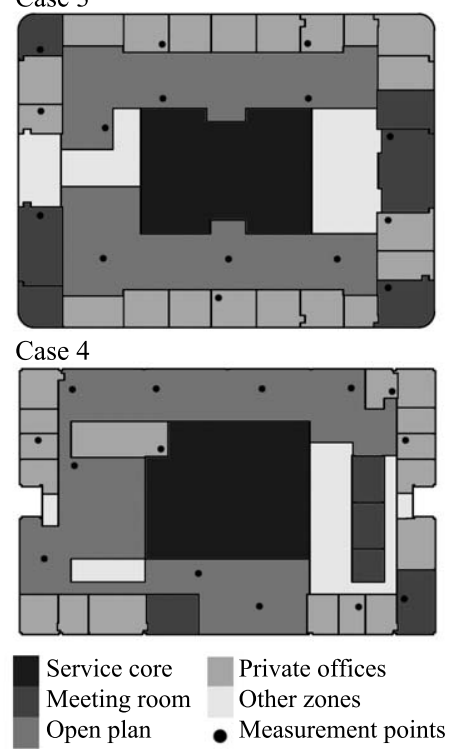

Fig. 2. Studied cases plan description.

to estimate temperature sensation and compare it to perceived thermal comfort. ${ }^{1}$ Also, daily maximum, minimum and average outdoor temperatures were included.

The questionnaire was applied to 138 randomly selected users distributed in the four cases described above. All selected users answered simultaneously the one-week survey four times throughout the year. With a total population of 361 office workers, the chosen sample allows us to establish a $95 \%$ of confidence level and a $6.5 \%$ margin of error.

Answers were collected online and on the same week per season in all four cases.

\footnotetext{
${ }^{1}$ For each of the questionnaires, the data from the nearest data logger was used, in order to assess thermal discrepancies between different zones of the floor.
} 


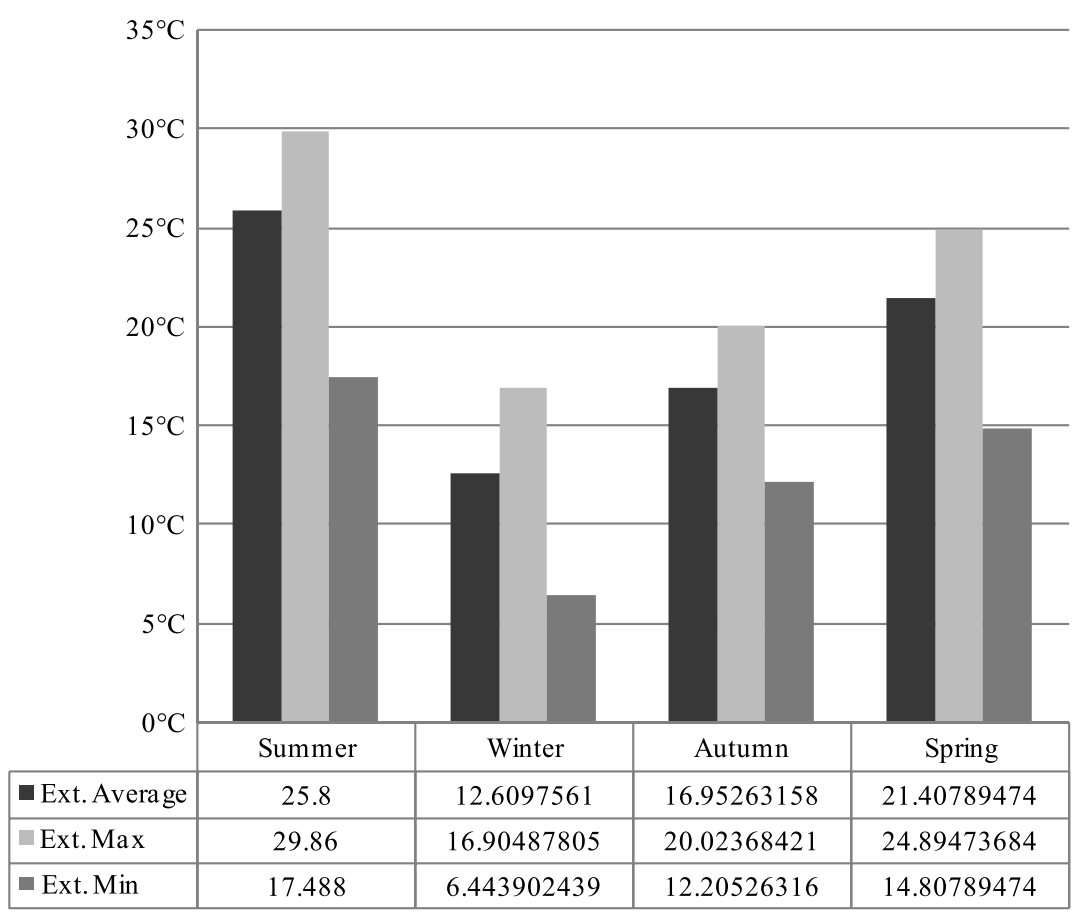

Fig. 3. Average external thermal measures by season.

\subsubsection{Descriptive analysis of the survey}

From a gender point of view, $73.2 \%(N=101)$ of the sample corresponds to male participants, and $26.8 \%(N=37)$ are women. Per ages, $64.5 \%(N=89)$ are 18 to 35 years old, $34.8 \%(N=48)$ are 36 to 50 years old and $0.7 \%(N=1)$ are over 51 years old. In terms of workspace, $47.8 \%(N=66)$ of survey participants stated they work in an open floor plan, $37.7 \%(N=52)$ shared their office and $14.5 \%$ $(N=20)$ had private offices.

Given that all offices included in this survey were mechanically conditioned by means of HVAC system, a comfortable environment at least in terms of thermal comfort was to be expected. However, $27.5 \%(N=38)$ of the participants declared that they had not felt thermally comfortable in their offices during the previous month. Furthermore, regarding specific thermal sensation, $28.3 \%(N=39)$ of the participants declared that they had felt either "hot" or "warm" at some point, $17.4 \%(N=24)$ stated having felt "cool" or "cold" and 54.3\% $(N=75)$ of the people expressed their perception of thermal comfort as "neutral". The latter was expected to be the most extensive answer given the use of air conditioning. For visual and acoustic comfort indicators, $21.7 \%(N=30)$ of the interviewed subjects declared that they did not feel comfortable in terms of visual conditions, and just $10.1 \%(N=14)$ declared acoustic discomfort in their workspace.

\subsubsection{Descriptive analysis of the measurements}

Maximum/minimum daily outdoor temperature measurements showed differences of up to $7.8^{\circ} \mathrm{C}$ (autumn) and $12.4^{\circ} \mathrm{C}$ (summer). Differences on average temperature reached to $13.9^{\circ} \mathrm{C}$ between 


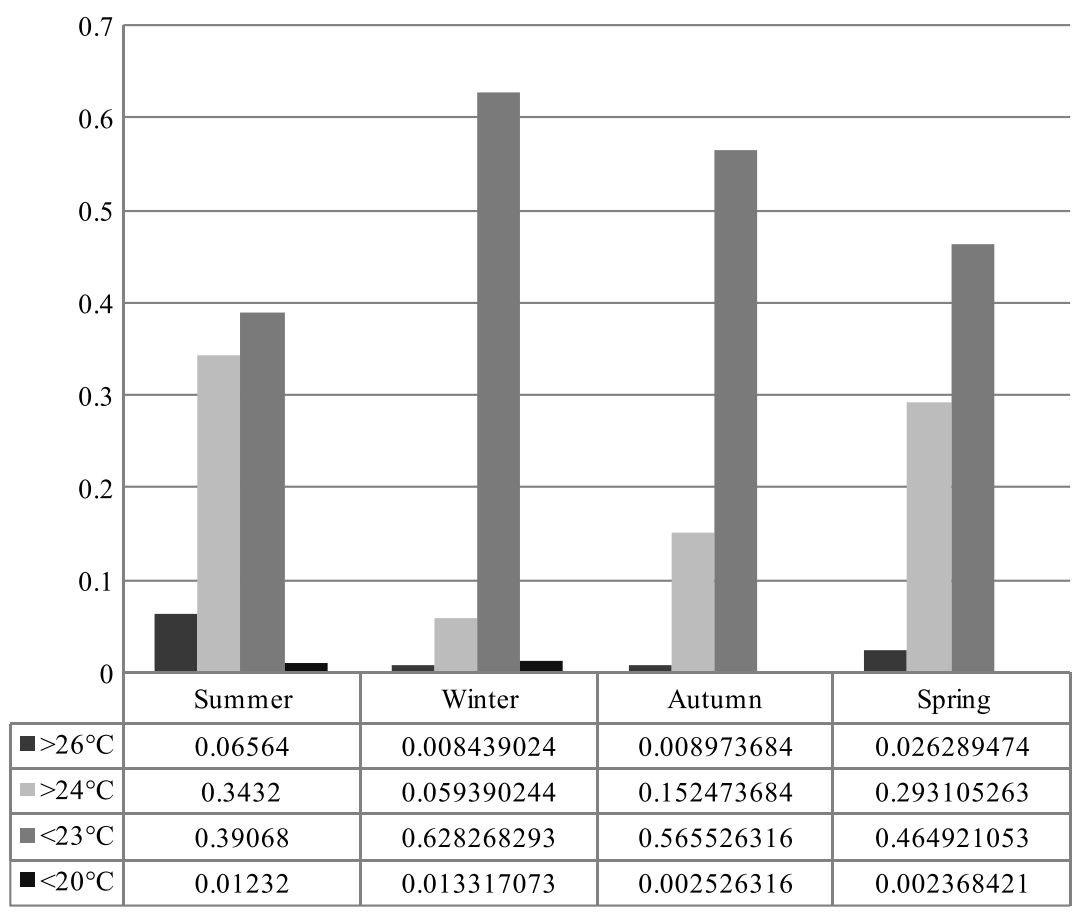

Fig. 4. Average internal thermal measures by season.

summer and winter, and $4.5^{\circ} \mathrm{C}$ between autumn and spring. Results are typical for Santiago, where large thermal differences are characteristic (Fig. 3). The results obtained per workspace and outdoor temperatures per surveyed week are shown in Figs. 3 and 4.

\subsection{Methodology of statistical analysis: Principal Component Analysis (PCA)}

Variables were analyzed using a Principal Component Analysis (PCA) to find the underlying structure of the data obtained from the survey and onsite measurements.

PCA is a statistic method capable of identifying inter-correlations among large numbers of variables, so as to infer the set of shared underlying factor or components (Hair \& Anderson, 2005). The goal is to condense information contained in the original variables into a smaller number of variables (aka components) causing a minimal loss of information. This allows researchers to establish the underlying structure of the array of original data.

For each analyzed variable, the PCA calculates the Pearson correlation coefficient of each component. Only statistically significant variables are considered (Table 4). Each component generates a set of new orthogonal variables with continuous values which are then allocated in the array of original data. In this study, values ranged from -2.43 to +3.73 (Table 5).

Variables were checked for information redundancy to ensure coherence between the resulting components and the theoretical framework of the study. Four components were established which allow us to holistically understand user comfort perception in the case studies. 
Table 4

PCA components

Factors

Relevance given by users to orientation for thermal comfort Relevance given by user to daylight excess for their lighting comfort

Relevance given by user to the lack of dayligth for their lighting comfort

Relevance given by user to reflection for their lighting comfort

Frequency that artificial lighting is used by users during last month

Time of day when artificial lighting is used by users

Relevance given by user to external noise for their acoustic comfort

Relevance of internal noise for acoustic comfort Thermal sensation of past 30 days declared by user Percentage hours above $26^{\circ} \mathrm{C}$, measured during the week that survey was responded
Comp. 1 (REF) Comp. 2 (ALF) Comp. 3 (TSO) Comp. 4 (RIF)

0,66

0,63

0,68

0,87

0,67

0,90

0,85

0,65

0,50

Table 5

PCA components description

\begin{tabular}{|c|c|c|c|c|}
\hline Value & Comp. 1 (REF) & Comp. 2 (ALF) & Comp. 3 (TSO) & Comp. 4 (RIF) \\
\hline Min & $-2,29$ & $-2,70$ & $-2,43$ & $-2,30$ \\
\hline Max & 1,87 & 1,12 & 3,73 & 2,54 \\
\hline Average & 0,00 & 0,00 & 0,00 & 0,00 \\
\hline
\end{tabular}

\subsubsection{Maps of Perceptions (MP)}

MPs attempt to visually display the comfort perception revealed by users in the survey. Given that each component allocates orthogonal factors to each variable of the array of original data, the variables can be graphed in correlation to the components. In addition, the factors of the original array can be grouped and graphed into families to reveal how the whole behaves in correlation with the components.

In MPs abscissas and ordinates correspond to PCA resulting components. In this study the data families are, namely, season of the year; study case; orientation; and workplaces with/without outdoor view.

\section{Results}

A Data Base including survey responses and measurements was set up. Nine data selected by PCA analysis were used to create four components, each one suggesting an aspect of user comfort percep- 
tion. Table 4 describes the factors comprised in each PCA component. The closer a PCA coefficient is to 1 , the higher the correlation. Positive values indicate a direct correlation with the component, whilst negative values indicate an inverse correlation. Table 5 contains maximum, minimum and average values of the factors associated to every survey response by component.

\subsection{Component 1: Relevance of External Factors (REF)}

REF comprises directly related factors which are conceptually linked to user comfort perception (Table 4). REF reflects the impact of the outside in indoor comfort, and thus survey questions for this component consider the incidence of outdoor environmental factors on user comfort perception, mainly lighting comfort. REF ranges from relevant to non-relevant.

Sun reflection received from neighboring buildings represents the highest score factor. All four cases are located in an urban context in which neighboring buildings are glazed. The survey indicated that both access as well as lack of daylight affected user comfort probably, being the latter a consequence of needing to use indoor screens as protection from the glare of other buildings. The relevance given by users to outdoor noise was rather surprising, particularly because these buildings have façade solutions which are soundproof and this factor was within the same range as the impact of natural lighting factors.

\subsection{Component 2: Artificial Lighting Frequency (ALF)}

ALF comprises two factors involving the frequency in the use of artificial lighting: daily and monthly use (Table 4). ALF ranges from high frequency to low frequency in use of artificial lighting.

The responses reflect the differences between types of workspaces, such as open floor plan offices or individual ones, as well as the ensuing management criteria and adaptive opportunities offered to users. The fact the PCA analysis considered both artificial lighting and natural lighting components can be understood as a architectural consequence due to the issue of glare in glazed facades. This critical problem generates many management strategies that affect user comfort perception. For example, the use of multilayer screens with blackout curtains and venetian blinds is a typical internal shading solution that leads to an unnecessary use of artificial lighting. This situation grants high coherence to the generation of this component in a comfort perception survey.

\subsection{Component 3: Thermal Sensation and Orientation (TSO)}

TSO describes thermal behavior at workspaces and comprises survey results as well as registered temperature data (Table 4). This is the only component in which qualitative aspects provided by survey were merged with on-site measurement registers. In general, qualitative and quantitative data are processed separately but the PCA analysis stated these were correlated and data was merged into one component: TSO. TSO ranges from warm to cold.

Two factors were extracted from the survey: last 30 days thermal sensation declared by users and the degree of relevance assigned by users to workspace orientation in their thermal sensation. The third factor was onsite measured temperature which was quantified as the percentage of hours in which the indoor temperature could be considered as not belonging to the comfort zone (above $\left.26^{\circ} \mathrm{C}\right)$. 


\subsection{Component 4: Relevance of Indoor Factors (RIF)}

RIF quantifies indoor space comfort perception, based on indoor conditions, specifically the incidence of indoor noise on acoustic comfort and the thermal sensation of last 30 days (Table 4). Value differences and the absence of more factors weakened this component, and thus, it was not considered in the maps of perceptions discussion.

\section{Discussion: Maps of Perceptions (MP)}

MPs were used to related pairs of components obtained by PCA. The goal was to graphically and holistically represent user perception. Axes represent positive and negative values for the various families of data obtained and onsite measurements for each family of data as a component valuation. The four quadrants allow for allocating the families of data so as to graph their behavior in relation to the components represented by each axis. In this study the families are: season, case, workspace type and possibility of outdoor view.

Season data corresponds to all the responses given by users per season in all the analyzed floors; case data is a separated view of every analyzed floor considering every season surveys together; the type of workspace is a segmentation data declared by users considering all analyzed floors together; and finally, the outdoor view options is a segmentation data too, that allow us to relate the component with the outdoor view options per season, considering all cases together.

\subsection{Map 1: General perception comfort (REF/TSO)}

Map 1 graphs the relationship among heat perception, outdoor lighting and acoustic comfort. These three factors account for the most common and easiest-to-ask aspects impacting on user comfort. TSO's scale ranged from hot to cold, with zero being a neutral thermal perception. REF's scale ranged from not relevant to relevant, with zero representing indifference. The ideal situation would be a zero reading for both components.

In the season analysis (Fig. 5), seasons paired into three pairs: winter and summer, and summerautumn and winter-spring. The winter and summer pair shows the largest differences in the TSO components and express the natural thermal difference in the cold and warm season. However, the other two pairs respond to different perceptions of the REF component: the REF components tend to be considered as relevant in winter-spring, and as less relevant in summer-autumn. Season analysis brings to light the fact that general comfort perception is influenced by thermal aspects as well as outdoor factors such as light and noise.

Cases also grouped into two pairs (Fig. 6) with different behaviors. The C4-C2 pair does not reveal any negative general comfort perception, while the C1-C3 pair does. Floor plans in C4 (Fig. 2) combine open floor plans facing north and south, and in C2 (Fig. 2) floor plans combine all types of workspaces with open floor plan facing south and east. Thus, these two cases are mixed floors. The C1-C3 pair shows an asymmetrical behavior, which could be explained by the cases' plan distribution: C1 (Fig. 2) is a low density floor with mostly single or shared offices -no open floor plan is considered-; while C3 (Fig. 2) is organized as an outer ring of offices and meeting rooms, with an indoor open floor plan which is not does not provide an outdoor view. Most users in both cases have no outdoor view. 


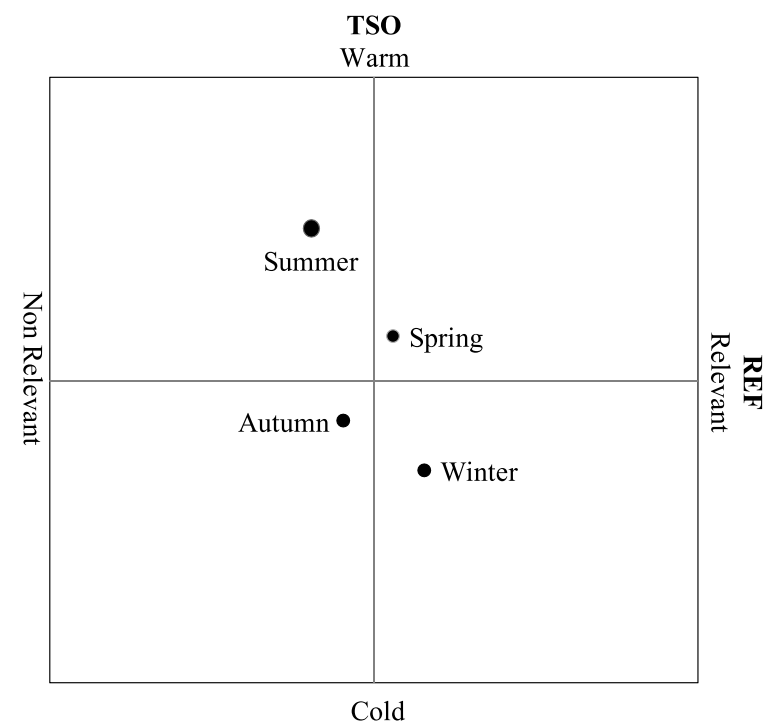

Fig. 5. Map 1: General perception comfort. Season analysis.

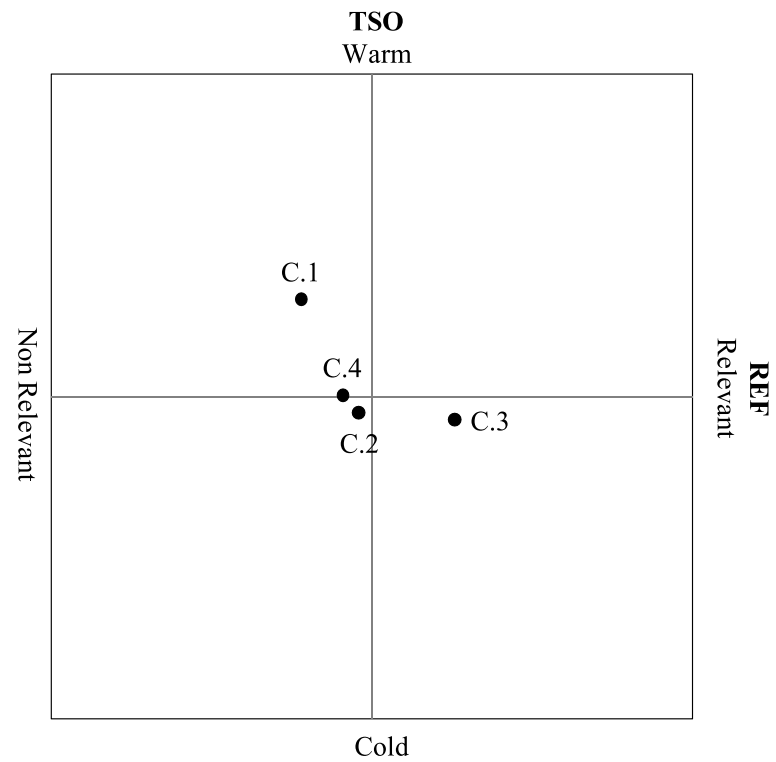

Fig. 6. Map 1: General perception comfort. Case study analysis.

The differences revealed by the case analysis in Map 1 allow us to assert that floor distribution may contribute significantly to general comfort perception.

Comfort perception differences are irrelevant considering types of workspaces (Fig. 7). The REF components tend to be less relevant among those working in open floor plan, perhaps because the depth of the floor does not provide for an outdoor view, particularly when blackout screens are 


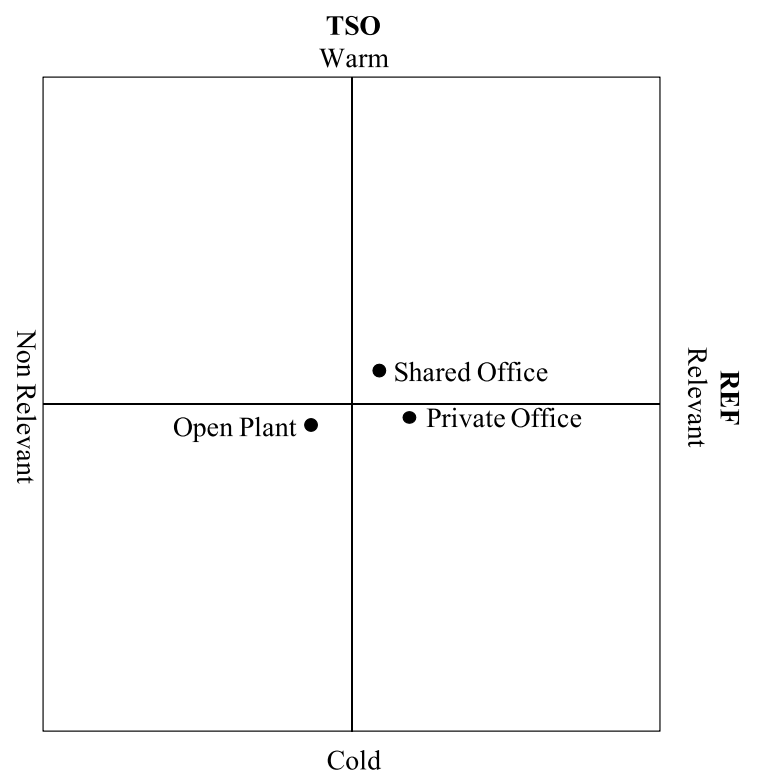

Fig. 7. Map 1: General perception comfort. Workspace analysis.

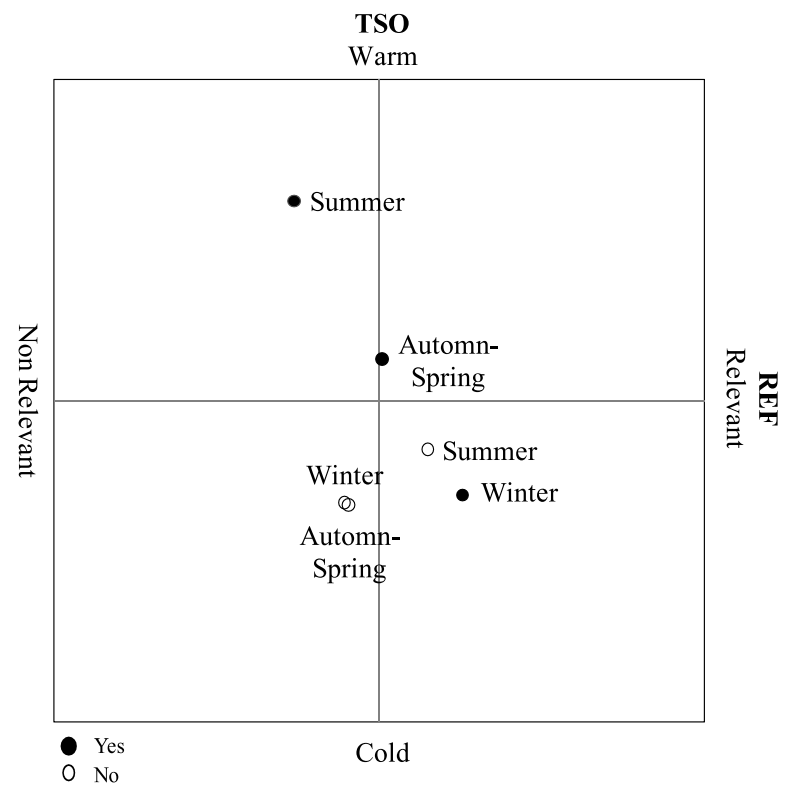

Fig. 8. Map 1: General perception comfort. Outdoor view analysis.

chosen as a light control method anytime throughout the day. Type of workspace is not relevant for general perception of comfort as can be seen in Map 1.

Data on seasonal perception throughout the year was only provided by those at workspaces with an outdoor view (Fig. 8). Our analysis revealed an unexpected fact in summer: having an outdoor 


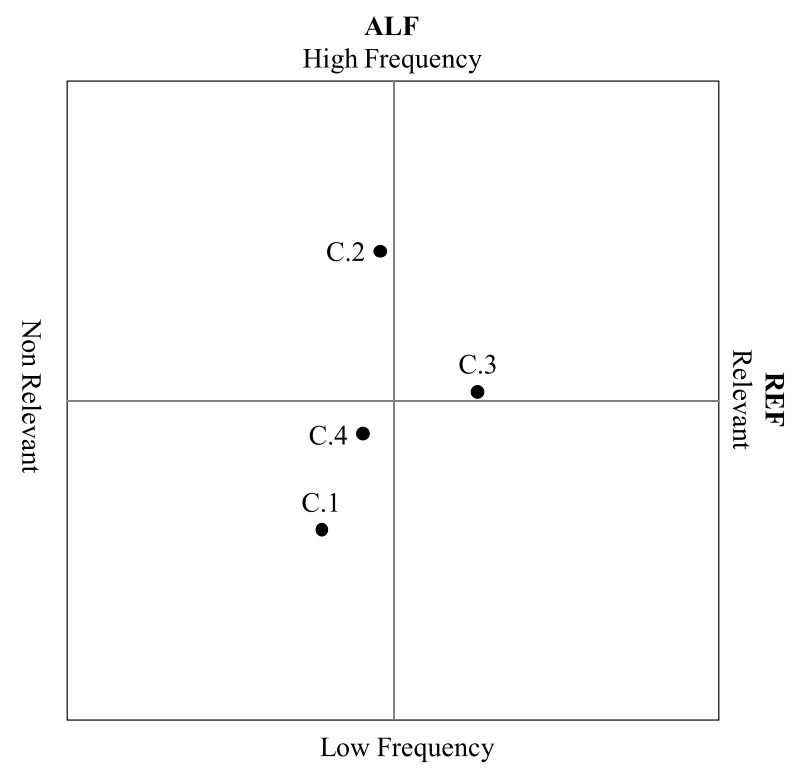

Fig. 9. Map 2: Lighting comfort perception. Case study analysis.

view appears to be another key issue affecting user comfort perception. Thus, floor distributions that create blind workspaces will have a low user comfort perceptions.

\subsection{Map 2: Lighting comfort perception (REF/ALF)}

Map 2 explains lighting comfort given that ALF includes data on the use of artificial lighting and REF the significance assigned to natural light for lighting comfort. REF's scale ranges from important to not important and ALF's from high to low frequency use of artificial lighting.

The analysis by case (Fig. 9) reveals some significant issues. In three of the four buildings, users do not related the frequency of use of artificial lighting (ALF) to outdoor factors (REF) which determine the need to use artificial light. This is the result of having protocols determining the use of artificial light regardless of users' visual needs. C3 is the only case in which users grant significance to the REF component. In this case some workspaces provide an outdoor view and others are totally blind, two extreme situations emphasizing the relevance to outdoor factors.

Workspace analysis reveals significant differences (Fig. 10). ALF component is highly rated by open plan users and poorly rated by private offices users. In general, differences in ALF rating are not associated to changes in the rating of the REF component, which can be interpreted as the fact that the use of artificial lighting is not perceived as an issue associated to outdoor factors which, in essence, should determine its use. Protection from the glare caused by curtain wall façades seems to account for this need to use artificial light when natural light is available.

Outdoor view (Fig. 11) clearly impacts on the ALF component. For all seasons, high ratings were provided by users without outdoor view and low, even negative values, are provided by those with outdoor views. This seems logical; however, the REF component does not reveal this behavior. Users 


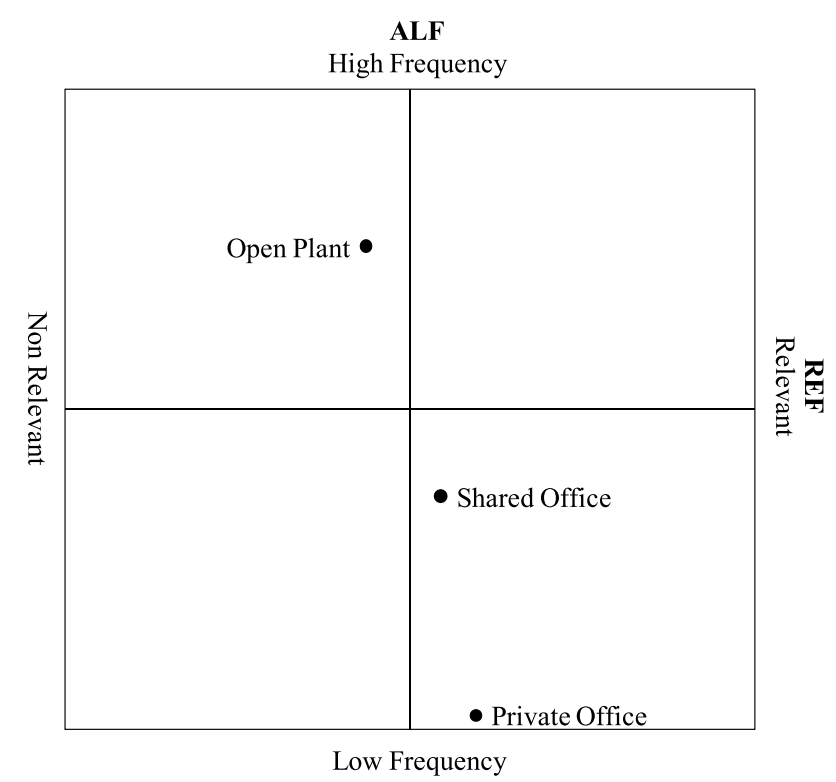

Fig. 10. Map 2: Lighting comfort perception. Workspace analysis.

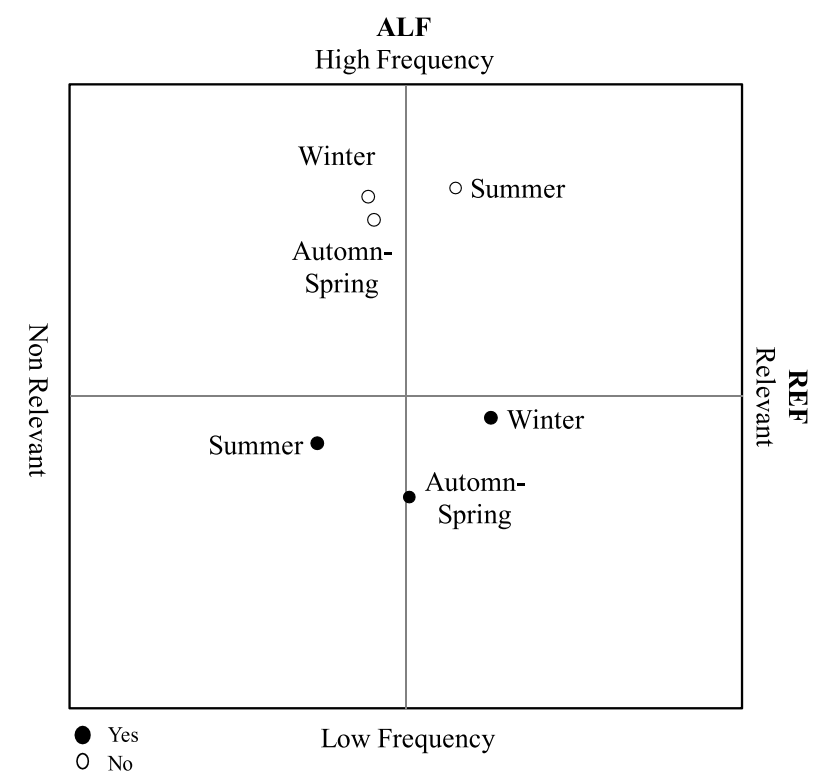

Fig. 11. Map 2: Lighting comfort perception. Outdoor view analysis.

with outdoor views rated the REF component positively in winter and negatively in summer and the opposite proved true for those without outdoor views. This proves the impact of having an outdoor view on lighting comfort perception. 


\subsection{Map 3: Thermal perception and use of artificial lighting (TSO/ALF)}

Map 3 would reveal the relation between artificial lighting use (ALF) and user thermal sensation (TSO). The scales and contents for these components have been previously explained in Maps 1 and 2.

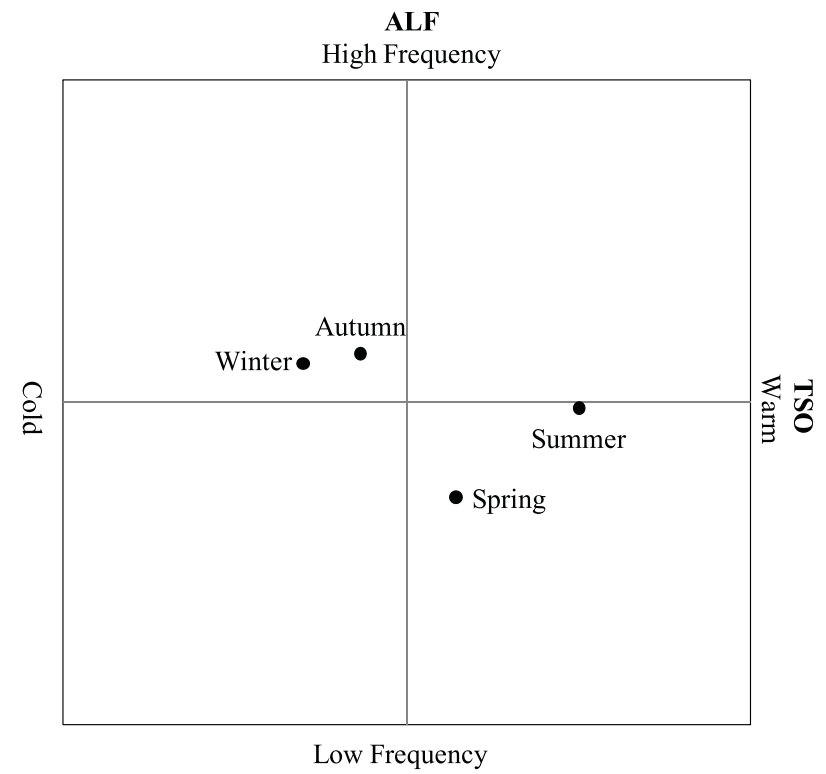

Fig. 12. Map 3: Thermal perception and use of artificial lighting. Season analysis.

ALF

High Frequency

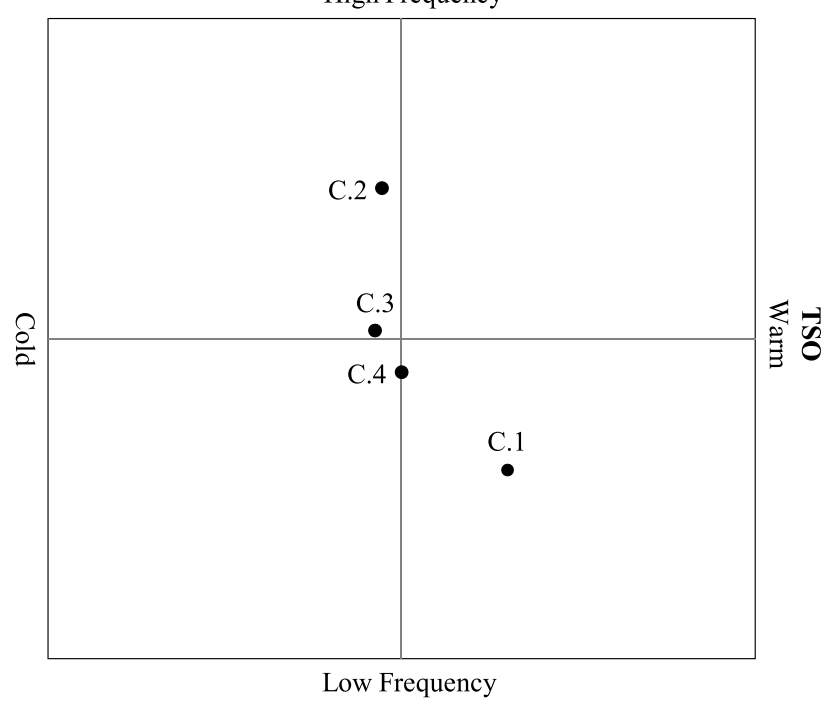

Fig. 13. Map 3: Thermal perception and use of artificial lighting. Case study analysis. 


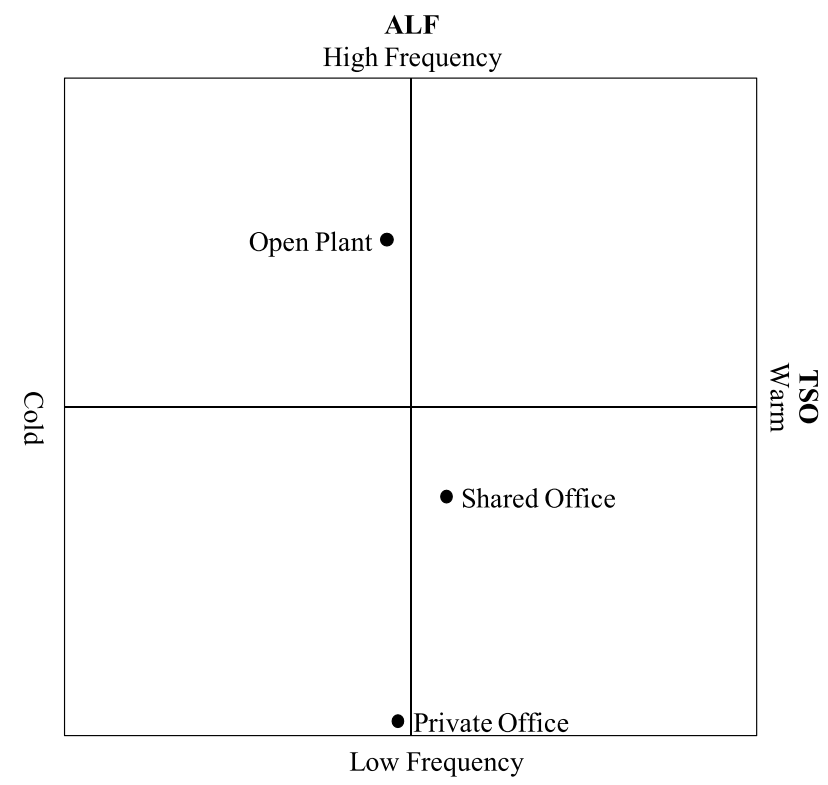

Fig. 14. Map 3: Thermal perception and use of artificial lighting. Workspace analysis.

Seasons analysis (Fig. 12) show pairs of cases sorted by thermal differences and natural lighting availability. The division between warm and cold seasons can be clearly seen. Coldest seasons are near zero. Warmer seasons generally show negative ALF values and positive TSO vales, especially on summer. As would be expected, seasons in which less artificial lighting is needed reveal positive TSO values.

Cases behave in pairs and are analyzed in Map 3 (Fig. 13). The values for the C3-C4 pair are practically zero. The behavior of the C1-C2 pair is extremely different. $\mathrm{C} 1$ is a low density floor and users are highly dependent on TSO component and not that dependent on ALF, whereas C2 has no, or practically no open floor plan, a feature also true for $\mathrm{C} 1$.

Finally, from the workspaces analysis (Fig. 14), workspaces and the ALF component seem very dependent, whereas workspaces and TSO seem practically independent. Lowest use of artificial lighting was stated by single offices users and highest use by open floor plan ones. The lack of relation between both component when they are observed by workspace, explain a high influence of lighting management because all cases, as was explained before, have lighting schedules no related with any logic criteria.

\section{Conclusions}

$3 \mathrm{MP}$ were produced based on three components obtained through PCA, crossing survey results sorted by: season, case, type of workspace and ability or non ability to see outside. The MP express general perception of thermal and lighting comfort on workspaces within the analyzed office buildings.

The conclusions were:

a) Thermal user perception does not follow the logic of seasonal thermal perception. All MP reveal show some aspect related whit light working together with thermal environmental situation. 
This emphasizes the need to consider workspaces lighting design to ensure satisfactory thermal perception.

b) Although the four cases correspond to typologically similar buildings, thermal comfort perception behaves differently in each one, and even more so lighting comfort. This demonstrates the need to coordinate the architectural design for workspaces and the building energy conception, a notion that is contradictory with the free floor design paradigm.

c) Comfort perception varies significantly among the type of workspace, namely, private office, shared office or open plan. This variation does not apply to thermal comfort but does impact heavily on lighting comfort. High frequency in the use of artificial lighting in the free floor area contrasts with the extremely low use in private offices. The use of artificial lighting is independent from outdoor factors but rather depends on how indoor lighting is managed in order to attain a general comfort perception. Thus, comfort perception, particularly regarding lighting comfort is related with façade design, due to high luminance derived from high glazing ratio within the analyzed buildings. The need to avoid glare -and the ensuing solutions and problems-, was present in every analyzed MP.

d) The main comfort issue in the analyzed office buildings, however, appears to be the impact of being able or not to see outside, a factor determined by thermal and lighting comfort. MPs allowed us to observe a consistent correlation between lighting and thermal comfort perception and the possibility of seeing outside. This architectural challenge in office building design must be taken into consideration given that an inability to see outside has a significant impact on general comfort perception.

Based on these results, we foresee various research lines to work on. Other types of office buildings need to be analyzed, starting by those in which there is an interest in improving comfort perception as well as those having a different kind of envelope strategy, given that curtain walls seem to negatively impact comfort perfection in high standard office buildings in Santiago.

\section{Acknowledgments}

This paper is part of a general research (FONDECYT Project \#11100143) funded by the Chilean Government through CONICYT, National Committee for Scientific and Technological Research, and sponsored by the Center for Sustainable Urban Development (CEDEUS) of the Catholic University of Chile (Pontificia Universidad Católica de Chile).

\section{References}

Andersen, R. V., Toftum, J., Andersen, K. K., \& Olesen, B. W. (2009). Survey of occupant behaviour and control of indoor environment in Danish dwellings. Energy and Buildings, 41, 11-16.

Azar, E., \& Menassa, C. (2012). A Comprehensive Analysis of the Impact of Occupancy Parameters in Energy Simulation of Commercial Buildings. Energy and Buildings, ELSEVIER (In review).

Encinas, F. (2004). The Technology Transfer of Double Skin Facades from Europe to Chile, an evaluation by means of CFD simulations, Dissertation submitted in partial fulfilment of the regulations for the Degree of Master of Science in Renewable Energy \& Architecture at the University of Nottingham, Nottingham.

Guerra Santin, O. (2011). Behavioural patterns and User Profiles related to energy consumption for heating. Energy and Buildings, 43, 2662-2672.

Hair, J., \& Anderson, R. (2005). Análisis Multivariante. McGraw Hill. 
Hummelgaard J., Juhl P., Saebjörnsson K., Clausen G., Toftum J., \& Langkilde G. (2007). Indoor air quality and occupant satisfaction in five mechanically and four naturally ventilated open-plan office buildings. Building and Environment, 42, 4051-4058.

Kwon S., Chun Ch., \& Kwak R. (2011). Relationship between quality of building maintenance management services for indoor environmental quality and occupant satisfaction. Building and Environment, 46, 2179-2185.

Macdonald, I., Clarke, J., \& Strachan, P. (1999). Assessing uncertainty in building simulation. Building Simulation 1999, Kyoto, Japan.

Olesen, B. W. (2011). Can we meet the ventilation required in international standards in an energy efficient way? Joint Conference 32nd AIVC Conference and 1st TightVent Conference: "Towards Optimal Airtightness Performance". Proceedings Presentations, 789-818. Brussels: AIVC, Air Infiltration and Ventilation Centre.

Pino, A., Bustamante, W., Escobar, R., \& Encinas, F. (2012) Thermal and lighting behavior of office buildings in Santiago de Chile. Energy and Buildings, 47, 441-449.

Roetzel, A., Tsangrassoulis, A., Dietrich, U., \& Busching, S. (2010). A review of occupant control of natural ventilation. Renewable and Sustainable Energy Reviews, 14, 1001-1013.

Yu, Z., Fung, B. C., Haghighat, F., Yoshino, H., \& Morofsky, E. (2011). A systematic procedure to study the influence of occupant behaviour on building energy consumption. Energy and Buildings, 43, 1409-1417.

Zhang, Y., \& Altan, H. (2011). A comparison of the occupant comfort in a conventional high-rise office block and a contemporary environmentally-concerned building. Building and Environment, 46, 535-545. 